\title{
Hyper Reality Theatre: Violating the Boundary of the Realism Structure through the Work "Theatre Lembu/Tepuk Amai-Amai"
}

\author{
Nor Shuradi Bin Haji Nor Hashim, Madya Mohd Kipli Abdul Rahman
}

\begin{abstract}
The millennial era of the 21st century has fallen witness to the emergence of popular artistic works that transcend beyond reality marks and serve as a condition of the hyper-reality world. In this context, this paper work argues that Malay theatre performance is a popular art form that has risen and built its own tendency as a post-modern art product that violates the realism structure boundary and acts as a hyper-reality world. This must have been caused by the Malay theatre direction that comes with recent directors who have the desire to violate this realism structure, in their assertion of new theatre performance forms. Related to this, our current paper work discusses the work directed by Namron entitled 'Lembu' and another one by Wan Khairunazwan Rodzy entitled 'Tepuk Amai-Amai' that have olated the boundary of the realism structure by forming themselves as hyper reality theatre. Using the non-structured observation method and the application of the hyper semiotics theory as the study's analysis outcome, this paper is able to explain the form of hyper reality theatre created by both directors as their effort to oppose to the realism theatre style in Malay theatre performance. This article's main discussion is based on the interpretation of the actors' acting form sign-system, the stage scenic sign-system, the stage lighting composition signsystem and the characters' costume sign-system that have been channelled to both theatres 'Lembu' and 'Tepuk Amai-Amai'. Thus, the findings in this article show that the actors' acting form sign-system, the stage scenic sign-system, the stage lighting composition sign-system and the characters' costume sign-system in 'Lembu' and 'Tepuk Amai-Amai' are the conditions of the proper sign, pseudo sign, false sign, recycle sign and superlative sign that mix together in the performance space. Thus, the integration among the proper sign, pseudo sign, false sign, recycle sign and superlative sign which overlap has led to this newly formed theatrical performance of Lembu and Tepuk AmaiAmai as hyper reality theatre and given a hyper-reality world experience into the staging Malay theatre today
\end{abstract}

Keyword: Hyper Reality, Hyper Semiotics, Realism Theatre.

Revised Manuscript Received on June 22, 2019.

Nor Shuradi Bin Haji Nor Hashim,Department of Performing Arts, Faculty Of Music and Performing Arts,Sultan Idris Education University, Malaysia

Madya Dr Mohd Kipli Abdul Rahman, Profesor,Department of Performing Arts, Faculty Of Music and Performing Arts,Sultan Idris Education University, Malaysia

\section{INTRODUCTION}

Realism theatre prioritizes the production of forms of characters' behaviour that imitates real human life from day to day; the linguistics symbols that utter daily language; the visual scenic stage that imitates from the real world situation; the props and costumes of the characters that represent the real world. (Schechner, 2013). However, the realism approach is not chosen by the line of production houses in contemporary modern Malay theatres. This is due to the fact that there are post-modern works that influence and draw the interest of the modern-day theatre directors in developing a new theatrical structure that violates the boundary of the realism structure. The growth of these post-modernism and post-structuralism schools of thinking has brought about various genres, techniques, sources that come from various cultures, eras and historical performances that have deviated from the realism in Malaysia. Thus, beginning from the 1970s, 1980s, 1990s and the 21 st century, wider, freer and more open space has been given to directors and local production houses to produce modern Malay theatres that have gone against realism. In documenting political polemics and socioeconomic issues of the Malay society when using theatre as the medium, it is established that directors and teams of productions have no longer created the performance text within realistic mode on stage. Reversibly, Malay theatre performance has been influenced by post-modernism by generating concepts in an abstract manner, avant-garde, metaphysic, the fusion of various techniques, media, also multi-cultures as a documentation tool for the local culture (Mana Sikana, 2017). However, this paper work sheds light on the argument raised by Baudrillard (2017) who debated that the condition of the 21st century also observes popular artistic works that have recreated themselves to transcend reality and to serve as the actual hyper reality. On this note, this paper work contends on the Malay theatre performance that follows the post-modernism world, it has built their tendency as a piece of art that moves towards these signified which violate the representation of the reality and which act as the world of hyper reality.

This current work also makes the assertion that directors and theatrical production houses are also part of the postindustrial and consumerism determined to produce the values of symbols that go beyond the reality reference when

Published By: 
they are performing in front of the audience. Thus, this paper work then argues over these days, post-modern Malay theatre is graced by a line of contemporary directors who have the willingness to violate the boundary of the realism structure to produce new form and meaning. On this vein, this paper work discusses theatrical works produced by Namron entitled 'Lembu' (in English) and Wan Khairunazwan Rodzy entitled 'Tepuk Amai-Amai' (in English) shown to the local audience. Both artists are postmodern Malay theatre's prolific directors that have past 15 years of experimentation, both of whom challenged the structure of realism as a mark of their effort in empowering the innovation of the non-realism Malay theatre performance.

\section{LITERATURE REVIEW}

The study of Malay dramas that are characteristically experimental and which violate the conventional rules of realism was carried out by Fazilah Hussain (2009) by looking into 44 Malay drama texts produced by local dramatists in two decades (1980s to 1990s). Using the structuralism approach as the study methodology, the close observation towards the study samples finds the existence of dramatic and narrative of the stage by way of experimentation also maintaining the hidden meaning of Malay culture. The outcome of this study has shown that local dramatists have used the local historical and cultural material, to the point that it marginalises the presence of Realism theatre on 44 modern Malay drama texts. The study outcome also concludes on the formation of the experimental Malay dramatic playwright in the 1970s, $1980 \mathrm{~s}$ and 1990s that had concentrated on folk experimentation themes. This demonstrates that the dramatic construction technique by experimentation has created a form of stage drama that is anti-realism but which still highlights meanings about the traditional value of Malays. Through the work written by Ghazali Ismail (2013) it shows that the narrative strategy produced by a local scriptwriter named Hatta Azad Khan also creates some dramatic effects through the use of props rich with elements of abstract symbols. The study outcome reveals that the scriptwriter Hatta Azad Khan also arranges object symbols like the setting, props and clothing with symbolism or surrealism orientation on the drama text. The conclusion of the study shows that the Malay drama text produced by Hatta also comprises of symbols, markers or images that can give various interpretations of meaning on the dialogues and actions. That said, this paper work raises the issue about the study of creative stage playwrights especially the fact that the corpus of the anti-realism drama study is different by understanding the theatrical performances. The direction of the dramatist is to translate the idea of creation into the dialogue used in the direction of the stage drama script. Unlike the theatre performance team whose role is to translate artistic events into performance, their source of work is the stage script. With that, the study by Fazilah Hussain (2009) and Ghazali Ismail (2013) only prepares a closer inspection on the corpus of research outcome which shows that local scriptwriters' attempt is to violate the stage dramatization texts in an anti-structuralism, anti-realism and experimental way. Meanwhile, the marking system on the form, technique, theme and structure of a modern Malay theatre performance has yet to be resolved by Fazilah Hussain (2009) and Ghazali Ismail (2013) on the corpus of the theatre performance research.

With that, the close observation on the knowledge corpus on the form of Malay theatre performance that violates the realism boundary staged around the 1970s and 1980s has been done by Nazri Ahmad (2003). Through the analysis of the form and content of the theatre 'Alang Rentak Seribu' staged in 1980s it is found that the director Syed Alwi has experimented in infusing the element of modern media into the slide and film, that does not only function to translate the symbol of the event using the multimedia technique. The multimedia tool, even, like the slide and film, can be manipulated to act symbolically to explain the meaning hidden in the drama. In brief, the study by Nazri Ahmad (2003) with regard to the form and content of the theatrical performance around the years of 1970s, 1980s and 1990s built by directors of Malay theatre finds that directors in those times liked to use sources from Malay traditional materials, like boria, dikir barat, wayang kulit, makyung, dance, songs and traditional music as the strategy in releasing the confine of the theatrical performance structure in the realist way.

Through the study by Shoon Choon Wee (2001) on the work of a local director Kristen Jit entitled "Skin Trilogy" produced in 1985 it uses the improvisation acting approach as the effort to challenge the form of realistic acting. Apart from that, the study finding also shows that Kristen Jit has used multi-media form along with other artists in dancing, acting, photo visual, graphics in a stage space collaboratively. It is concluded that the director also runs from this realism boundary by interpreting the discreet meaning surrounding the social and cultural formation of the Malaysian society at the time. Also, the corpus about the directing style of anti-realism Malay theatre has been done by Syarafina Abdullah (2016) as she looks into the role of local prolific woman directors in giving their reactions to the lives of the people in the society. Through the study of the directing style of a Malay woman director, Rohani Md. Yousoff it is found that she is influenced by the spirit of the Brechtian Epic Theatre which is already known as a challenge to the Aristotelian and Realism theatre styles. Thus, the works done by Shoon Choon Wee (2001) and Syarafina Abdullah (2016) again illustrate that the local Malay theatre has the effort to escape from realism by recounting the surroundings and Brechtian epic theatre when dealing with issues of the local society today into the modern theatre.

The research by Syarul Fitri Musa (2018) also exposes about the recollection of the concept of minimalism as an approach adopted by Dinsman, A.Wahab Hamzah, Aloy Paradoks and Fasyali Fadzly while they were criticising about the conflicts of contemporary society using small stage space located in the Store of the Dewan Bahasa dan 
Pustaka Theatre, Kuala Lumpur. The research outcome has shown that the sample of works of Malay theatre performance produced by Dinsman, A.Wahab Hamzah, Aloy Paradoks and Fasyali Fadzly from the year 2003 and 2014 has challenged the order of realism by way of completing the concept of minimalism as the matrix of performance. In reference to the literature review, it shows that indeed, the form of Malay theatre that violates the boundary of the realism structure with the insertion of hyper reality has yet to be addressed, in terms of the studies done on this phenomenon. To bridge the gap of knowledge, the roles of the directors Namron and Wan Khairunazwan Rodzy have manipulated the acting system, stage setting and the costume by way of hyper reality on their work are thought to be relevant.

\section{STUDY METHODOLOGY}

Our study methodology uses the qualitative approach. To obtain our study data that is rich with information, this research adopts the observation method. The observation method developed from this qualitative study is not only limited by the data recording process from the surrounding during the performance. The researcher is able to listen closely, observe and organize the data so that the whole data gathered and interpreted bring meaning to this current work. Thus, the observation method used in the research will be using the non-structured observation method. This method enables the researcher to observe this natural theatrical performance. This is harmonious with the observation method that not only requires data researcher from their viewing of the play, but they also need to observe the performance through is shown live. In one angle, this research has developed the observation method according to the role played by the researcher to determine the type and quality of the observation. Thus, this research has chosen the category of 'full-scale observer' that requires the researcher to function as an observer to justify the study phenomenon. In line with this, the study methodology has gathered data from the observation of the performance using visual recording and the performance audio. This paper work again, asserts that the observation method also allows the researcher to record the performing arts to enable an analysis to be done repeatedly and in detail. This is important to assist the researcher to reconsider the markers found in the recording data after the data has been gathered. This is done by checking again the markers throughout the show as recorded through the visual recording and audio over and over again, and reinterpreting them for coding purpose. Also, the data gathering procedure also encompasses the steps that need to be taken to obtain information related to the study phenomenon from the secondary data resources, library study and electronic media references. This is to solve the issue of this hyper reality created by theatre directors as an opposition to realism in the post-modern Malay theatre. Thus, this paper work applies the hyper semiotics theory that's coined by Pilliang (2010). Indeed, Pilliang (2010) asserts that hyper semiotics continues to create sign or signifier that are in tandem with the features (2) marked as simulation - which is the creation of objects that no longer refer to the representation of reality. It is pointed out that hyper semiotics refers to the production of signs that go beyond the semiotic boundary marked by the violation of the reality boundary so much so that the world of hyper reality built in the space of 'simulation' appears to be more believable and more real than the actual reality. In relation to this, Pilliang (2010) points out that the condition of hyper reality exists when five (5) marks covering proper sign, pseudo sign, false sign, recycle sign and superlative sign have interwoven to form the sign system on the literary text. The proper sign condition refers to the sign that has the association of reference or the concept representing the reality. Thus, proper sign is categorized as a signification, which means that it is a sign reflection of a basic. The pseudo sign refers to the sign that is not genuine, superficial and pretentious. With that, the pseudo sign condition refers to the sign that pretentiously draws upon the reality. In fact, the sign is a lie and acts as a pervasive mask to the reality. For false sign there is an imbalance between the sign and the reality found on the sign. Sign A does not reflect sign A, as it actually portrays sign B. This is because, there has been a manipulation, by way of deceiving the meaning of the reference and the actual reality. The recycle sign condition is a sign that always pursues a new time-space context as the events or the reality of the past were made vacant from the real meanings. Thus, all the objects that fill and redevelop new signs follow the latest context which is altogether different or not in any way related to the real life reference. Meanwhile, the superlative sign refers to the sign that portrays hyper signification and go beyond the real-life references. The superlative sign can be seen through the Hollywood filming arts which presents the genres of war, action and fantasy with offering of the hyper sign such as the effect of war, the effect of violence, the effect of fight, and fear at the expense of creating an extraordinary impact that transcends healthy minds and the real world boundaries.In brief, Pilliang (2010) asserts that the mix-up of the proper sign, pseudo sign, false sign, recycle sign and superlative sign have overlapped behind an artistic work and create the conditions as hyper reality and simulacrum.

\section{ANALYSIS AND DISCUSSION}

'Lembu' revolves around the conflict surrounding villagers when there is a rumour that a 'big' leader is coming to visit their place. However, the visit is frowned upon by Haji Suhaimi and he protests the fact that Datuk Hassan is having a ceremony to celebrate the leader's visit to the village. With that, various slanderous words are thrown by Haji Suhaimi to Datuk Hassan throughout the grand preparation for the visit.

The argument between Haji Suhaimi and Datuk Hassan also leaves an impact to the entire village so much so that their relationship becomes tense before the preparation even begins. Meanwhile, the story of Tepuk Amai-Amai portrays the lives of six secondary school students who have this pressure when dealing with their studies. 
They have to fulfil their family's dreams and the school wants to get good results for the school. In reality, they are unable to excel in their studies due to their parents' negative attitude and the pressure exerted by their own teachers. The theatre performance of Lembu was shown in front of the audience in DPAC in 2014 whereas Tepuk Amai-Amai was staged at the Culture Centre, Mara Technology University (UiTM) in 2015. Thus, in this section, the article discussion is based on the interpretation of the acting marker, the setting, the lighting composition and the costume of the characters channelled to the theatres 'Lembu' and 'Tepuk Amai-Amai'. Using the hyper-semiotics theoretical approach, it is found that the acting, stage setting, lighting composition and the costume of 'Lembu' and 'Tepuk AmaiAmai' are the conditions of the proper sign, pseudo sign, false sign, recycle sign and superlative sign that have become intertwined and formed a Hyper Reality world.

\section{The Superlative Sign Condition on the Acting}

Through the analysis of the performer's sign-system found a female actor who played the role of Datuk Hassan, Haji Suhaimi, Hadi, Tok Aki, Tok Aki’s wife, Maziah, Kak Yah Murai and Mak Piah in 'Lembu' was not revealing a realistic and representational acting manner. This shows that the female actor does not display the realism acting that can be known, experienced or identified by audience. Reversibly, the form of acting drives towards the superlative sign condition when it is able to amplifythe signifier of actor's body language in a 'hyper semiotics' way. This is evident when the female actor translates her body action signifier in an extreme manner by changing to multiple characters only by manipulating her body. She is able to challenge and her normal and realistic body. Simultaneously, she is able to create a hybrid acting technique that goes beyond normal minds and the boundary of real life for an ordinary man. This hybrid acting technique is able to generate the superlative sign condition as the actor is able to switching her body symbol from one character to another only using her body. Thus, the superlative sign as shown in Lembu is evident through the actor's first appearance as a villager named Mak Piah. By demonstrating the sign of an old woman walking, and showing a worried expression as if she is looking for something, this female actor is able to assert the meaning that she is worried about her missing cow. After interacting with the audience as she is asking about her cow, the scene of 'Lembu' changes when she transforms her body symbol from being Mak Piah, to being Datuk Hassan, a man who is also the head of the villager. In the scene, Datuk Hassan has chaired a meeting with the villagers because a leader is coming to their village. The actor is able to illustrate Datuk Hassan's characteristicshe has a sense of leadership, he is very influential in power and dominant. After this scene, the superlative sign condition further shows when she switching from being as Datuk Hassan, then change hers role of Haji Suhaimi. She is able to show the characteristics of Haji Suhaimi, as someone who does not agree with Datuk Hassan who wants to do all the extravagant celebratory ceremony for this very important visitor. Haji Suhaimi is also depicted as accusing Datuk Hassan as a village leader who only concerns with sugarcoating the leader for his own means. Next, the actor

further exposes the superlative sign by changing into the character of Tok Aki as both husband and wife. While playing the role of Tok Aki and his wife, the female actor is able to pull off the scene when both husband and wife argue with each other only because of this visit by the leader. Even so, as the climax of the scene, the female actor is able to play the role as the husband and use his patriarchal power by threatening to divorce his wife if she protests. After she manages to show this heated argument, she then transforms into another character, who is Kak Yah Murai. In this character, this female actor is able to expose herself as a strong-willed woman who gossips around about the bickering between Toki Aki and his wife, including the cold war between Datuk Hassan and Haji Suhaimi and other villagers. The actor further exposes the superlative sign condition when again, she changes into the character of Maziah and Hadi alternately. When she plays the role of Maziah, she is able to highlight the personality of a woman who is very alluring, childish, even, while showing the erotic expression, gesture, and body movements. Her eroticism is evident when she seeks for her lover's attention - she becomes seductive, persistent and sexual with him. When she becomes Hadi, she plays off the stereotypical trait of a heterosexual masculinity by talking in a romantic, soft way. However, gradually, Hadi who starts off joking around with Maziah in the bush in the village is found to change to another motive. This time, he wants to have sex with her. Thus, the ending of this story of 'Lembu'where the villagers argue over the leader's visit, it exposes the condition of the superlative sign when the body of the woman actor changes to both characters, Hadi and Maziah. She then becomes the character of Kak Yah Murai who is portrayed as visiting the wedding ceremony of Maziah and Hadi. At this point, the character of Kak Yah Murai is shown as being busy entertaining her guests with such talkative and loud manner.
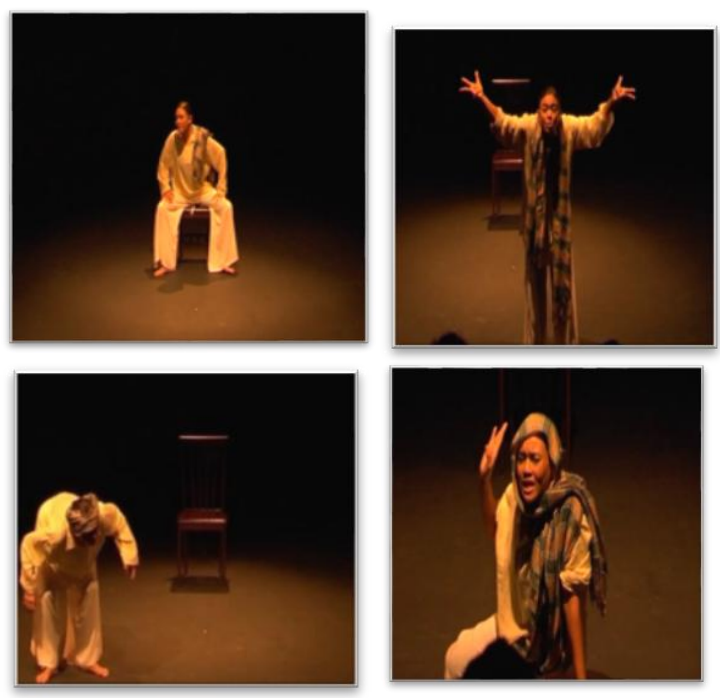

Fig. 1 The actor produces superlative sign using hybrid acting techniques by switching her body symbols from one character to another character in 'Lembu' performances.

Published By: 
Through the performance of Tepuk Amai-Amai, the acting form no longer plays around with the six actors bodies to represent the characters - students, mother, father, family members, school principal, disciplinary teacher, religious teacher, counselling teacher, reporters and school teacher, whom cater to the convention and order of realistic acting. Here, there is no more one actor to serve the role of the characters to resemble the lives of a human on stage which are identifiable, experienced and identified by the audience. In turn, the acting form for Tepuk Amai-Amai only requires six actors to embodiment all these different characters- from students switching being asstudents, parents,family members, school teachers and proceeding to the role of the reporters. Hence, by manipulating and exploiting the human real bodies comprising of three female actors and three male actors, the superlative sign condition is able to be constructed by signifier these body and allowing them to play the roles of Dira, Topex, Nana, Aloy, Afiq, Nadirah, Nadirah's mother, Afiq's mother, Aloy's father, Topex's mother, Nana's father, Dira's grandfather, School Principal, Disciplinary Teacher, Religious Teacher, Administrative Teacher, Reporter 1, Reporter 2, Reporter 3, Reporter 4, reporter 5, reporter 6 and the Minister of Education throughout the performance. Again, the acting form demonstrates the superlative sign condition as realism acting no longer becomes a chosen approach. Even more so, the superlative sign is highlighted by improving the six actors' body using the hybrid acting approach. This is evident when all six actors have manipulated their body signifiers by switching the role symbol from year 1 student, to secondary school students, school teachers, parents, family members, symbolic chorus, the Minister and the reporters repeatedly.
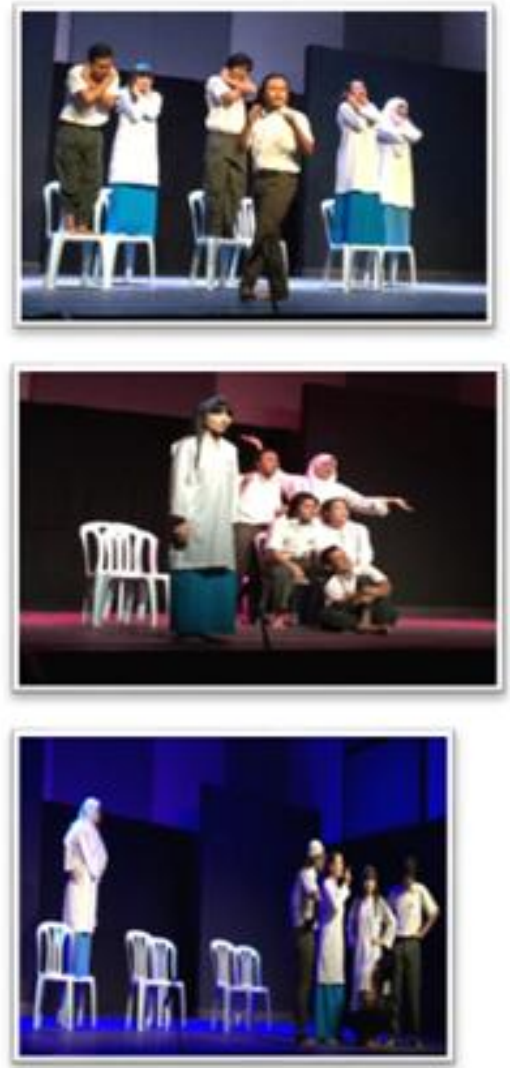

Fig. 2 Six actors generate the superlative sign condition using hybrid acting technique in 'Tepuk Amai-Amai' performances.

In conclusion, the acting form in 'Lembu' and 'Tepuk Amai-Amai' is the superlative sign condition when it is able to expand the signifier of the actors' body action in a hyper reality mode. It is practiced by allowing the body to translate its own action in extreme way by of switching the symbol of the roles played. This automatically challenges his or her own normal and realistic body. Also, it is able to create an impact of acting that goes beyond normal minds and beyond the boundary of an ordinary human life.

The Condition of the Superlative Sign On The Stage Set and The Stage Lighting Composition

The story of 'Lembu' is based on the lives of village people, or Malays in the rural area. Irrespective, it is found that the stage scenic set is not complete with the right structures or landscapes representative of Malay villages that resembles that in real life. In turn, 'Lembu' is only equipped with a set of chairs and empty stage space but it can still translate into the locations of the event. The strategy is to manipulate the set of chairs placed on the empty stage, which is when actors playing the roles of Datuk Hassan, Haji Suhaimi, Tok Aki (husband and wife), Kak Yah Murai, Maziah, Hadi and Mak Piah use their imagination to portray their roles without having to require all these physical structures like village houses, rooms, village landscape, in a realistic way.

With only a set of chairs and an empty stage, actors only need to play with their own imagination to assert themselves in every space, time and event background from one scene to another.

For the setting of 'Tepuk Amai-Amai' spaces involve the school vicinity, home, public areas and the mass communication building. Therefore, in the scene, the stage scenic setting is not complete with the construction of structures that can depict the school area, its building, teachers' meeting room, classroom, home areas, the yard that are realistic or which resemble the real world. By contrast, the stage set is the mark of the superlative sign only based on the (6) chairs to depict the meaning of the scenario. Thus, the superlative sign exists when all these six actors need their own imagination to portray himself with other characters in every space, time and setting. On this note, the stage setting background marker for 'Lembu' by Namron and 'Tepuk Amai-Amai' by Wan Khairunazwan Rody is a superlative sign when the actor is able to asserts herself in the time, scenario by engaging himself into the transition of the role and conflict that occurs. Although the setting for 'Lembu' and 'Tepuk Amai-Amai' is not complete with a realistic physical structure, the actor/character allows himself to act as if he/she is in that actual setting without having to have the physical structure like public areas, school building, classroom and home on the stage. 
Meanwhile, the lighting composition for both performances does not expose the lights to support a natural theatrical effect lighting mood. In return, the lighting design composition developed in the stage setting of the plays 'Lembu' and 'Tepuk Amai-Amai' has generated the concept of abstract theatrical effect lights so much that the stage background has become extreme. This is evident when the low key effect and the high-intensity lighting focus effect shine on the body of the female actor during the scene. Thus, the use of the low key technique not only brings out strange, surreal and fantastical theatrical lights, due to the effect of the black shadows surrounding the characters, but also generates the effect of high intensity light to help the audience concentrate fully to the actor's body to help them better understand the conflict that is experienced by the character. This disagrees with the natural theatrical effect lights that still try to evoke the mood, setting and background as the images of the real world on the stage. In short, as the result of the use of the abstract theatrical lights as the lighting the mood is evoked and automatically it becomes far from being realistic. Indeed, the abstract theatrical effect lights composition is also generated due to the use of multi-coloured filters that can highlight the setting, mood and event on both the theatrical plays of Lembu and Tepuk Amai-Amai.
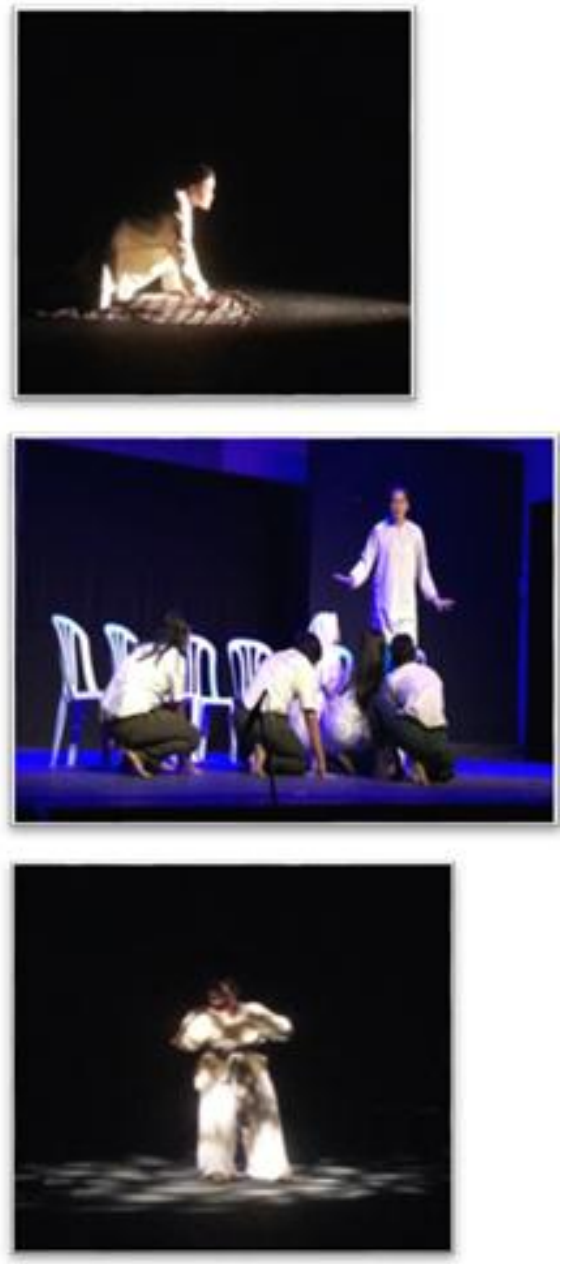

Fig. 3 The forms of scenic stage background, stage lighting composition and the characters costume that given a hyper-reality world experience into the staging Malay theatre today.
The Conditions of Proper Sign, Pseudo Sign and False in The Characters' Costume

Indeed, the story of 'Lembu' depicts eight (8) characters comprising of Datuk Hassan, Haji Suhaimi, Tok Aki the husband, Tok Aki the wife, Maziah, Abang Hadi, Kak Yah Murai and Mak Piah by only manipulating asingle female body. Thus, this female actor is only wearing a top, a pair of pants, and a long shawl in pastel brown to represent all the individual characters namely Datuk Hassan, Haji Suhaimi, Tok Aki the husband, Tok Aki the wife, Maziah, Abang Hadi, Kak Yah Murai and Mak Piah clearly with different personalities, social background and gender background. Therefore, the costume worn in Lembu is the pseudo sign condition. The actor keeps this clothing throughout the play, and retains all these characters without changing the clothes to follow all these different social backgrounds and costume of every character. This contradicts the order of realism which requires actors to wear clothing that is appropriate to the social background, and is thus, believable by the audience according to the real life situations.

Thus, the pseudo sign condition on the aspect of costume can be observed at the beginning of the performance, when the woman actor loses her role as Mak Piah who is looking for her missing cow. In this scene, the character of Mak Piah wears a long-sleeved shirt in pastel, a pair of pants also in pastel and a long batik sarong. However, when she changes from being Mak Piah to Datuk Hassan, she still wears the same pastel shirt and pants. What makes the identity, personality and costume different between, Mak Piah and Datuk Hassan is the manipulative effect of the long shawl that she rests around her body.

Basically, there is a long fabric wrapped around the actor's head to assert herself as Mak Piah. Nevertheless, when the female actor transforms herself into the character of Datuk Hassan, she will first remove the shawl from the head. She will then place the shawl on her left shoulder to assert her identity as the character of Datuk Hassan. The next evidence of pseudo sign is when she removes the shawl from her shoulder and puts it on her neck to become Haji Suhaimi. Next, from the character of Suhaimi to that of Kak Yah Murai, she will remove the shawl from her neck. She then places it on her head to assert herself as the character of Kak Yah Murai who still observes her aurah as a Muslim woman. Then, the pseudo sign condition on the costume can be observed during the scene when the characters of Maziah and Hadi are joking around in the forest. Through this scene, the pastel suit remains. Again, these characters are differentiated through the styling and manipulation of the shawl. The female actor would place the shawl on her head and she will let it loose downwards. This kind of manipulation shows the character of Maziah as an erotic and seductive woman. Meanwhile the identity of Hadi is differentiated by her tying the shawl around her waist. Through this, this female actor is able to show that he is a dominant, superior male character. 
Briefly put, the pseudo sign condition refers to the sign of characters' costume that intends to sketch a reality. In actual fact, this sign is a façade and acts pervasively by allowing a female actor to wear the same type of clothing but still able to assert herself through the eight characters that have different social, personality and gender backgrounds. This is made possible by manipulating the use of the long shawl on the body of the actor to show the transition from one character to another character.

Meanwhile, three female actors who performed 'Tepuk Amai-Amai' have been found wearing baju kurung and the school skirt representing the characters of Dira, Nadirah, Nana, Dira's mother, the chorus, Afiq's mother, the female teacher, counselling teacher, Year 1 students, a female newsreader, a female reporter, and a female religious teacher, certainly with different personalities. Meanwhile, the male actors wear a white short-sleeved shirt, green pants, to represent the character of Afiq, Topex, Aloy, Atok, the Minister, School Principal, a religious teacher, Aloy's father, Nana's father, the guys, Year 1 students and male newsreader and reporters with different personalities. On this vein, the meaning analysis on the costume of the 'Tepuk Amai-Amai' performances is a false sign condition, following the aspect of the school-wearing in Malaysia. It thus, contradicts the costume worn by the character of Afiq's mother, the teacher, the counselling teacher, good female student, Year 1 female students, also the characters of the newsreader, reporter and Ustazah that have their own clothing code and with reality reference identifiable by the audience. It is the same case with the male actors. The male actors remain wearing the secondary school uniforms although both male and female actors play the role of the Minister, school principal, Ustaz, Aloy's father, Nana's father, the guys, Year 1 male students not to mention both the newsreader and the reporter. Wearing baju kurung with blue skirt for female actors and white shirt and green pants for male actors does not show any sign that is not at all related to the element of truth in the reality. Hence, the wearing of secondary school uniform worn by the characters of the school teacher, Year 1 student, the Minister of Education, the mother, the father, the family members, the reporter and the newsreader has created a rather imbalanced relationship between the characters costumes and the reality of the wearing of the clothes. With that, the characters costume worn is the hyper-reality condition because it does not describe the clothing code as known by the audience in real life. However, when the six actors play the roles of Dira, Nadirah, Nana, Aloy, Topex and Afiq who are secondary school students, the wearing of the school codes by gender is in line with the proper sign. This follows the fact that the wearing of school uniform by Dira, Nadirah, Nana, Aloy, Topex and Afiq represents the actual school uniform code worn by Malaysian students. In sum, the costume-wearing in both theatrical plays overlaps with the proper sign, pseudo sign and false sign until the implication challenges the costume of the characters that deviates from the actual reality that we experience.

\section{CONCLUSION}

In portraying the polemic of politic and the problems surrounding the education among the Malays, it is found that realism is no more a choice, for directors Namron and Wan Khairunazwan Rodzy in producing a theatrical performance. It shows that both directors are revolutionary artist who have the determination of produce those values of symbols that deviate from the references of reality when addressing socio-political issues in front of live audience. Thus, this millennium has seen popular art products through the Malay theatre performance to also develop some hypermarkers, transcending the reality and acts as the actual hyper-reality. Based on the analysis outcome of the acting sign-system, stage scenic background sign-system, stage lighting composition sign-system and the costume of the theatre performances 'Lembu' and 'Tepuk Amai-Amai' sign-system as a whole they are the conditions of proper sign, pseudo sign, false sign, recycle sign and superlative sign that are intertwined in a performance space. This leads to the interwoven forms of acting sign-system, stage scenic background sign-system, stage lighting composition signsystem, the costume and later become a hyper reality theatre. This is at par with the hyper semiotics theoretical framework that asserts that behind any art work, hyper reality acts as a simulacrum.

Related to this, this paper work points out that the Malay theatre performance is a popular art that builds its own tendency to become a postmodernism art that violates the boundary of the realism structure, acting as a hyper reality theatre and gives a hyper reality experience during the shows of 'Lembu' and 'Tepuk Amai-Amai' for the viewing pleasure of the spectators.

\section{ACKNOWLEDGEMENT}

This research is funded by University Research Grant (GPU) - (2015-0070-107-010) Geran Penyelidikan Universiti (GPU) from Universiti Pendidikan Sultan Idris. Part of this research was presented and published as proceedings in International Conference on Development of Education, Environment, Tourism, Economics, Politics, Arts and Heritage (ICDETAH 2015) held from 23-26 November 2015 , with proceedings in the 2nd Cultural Identity Seminar Malaysia, held from 10 December 2016.

\section{REFERENCE}

1. Baudrillard, J. (2017). Symbolic Exchanged and Death. (L. Hamilton, Trans.). New York, NY:Sage.

2. Fazilah Husin. (2010) Teater Melayu. Teks dan Eksperimentasi. Kuala Lumpur. Dewan Budaya dan Pustaka.

3. Ghazali Ismail.(2013). "Suara-Suara Kecil” Laungan Hatta Azad Khan dan Strategi Naratifnya: Penilaian Kritis Terhadap Drama Pentas Hatta dari Perspektif Sosiologi Sastera. Tesis Ijazah Sarjana Doktor Falsafah. Universiti Sains Malaysia.

4. Mana Sikana. (2017). Di atas Pentas Drama Melayu Pascamoden. Kuala Lumpur: Institut Terjemahan \& Buku Malaysia.

5. Mohd Nazri Ahmad, (2000). Seni Persembahan Drama Melayu Moden Malaysia. Bangi. Penerbit Universiti Kebangsaan Malaysia. 
6. Pilliang, Yasraf Amir.(2010). Hipersemiotika: Tafsir Cultural Studies atas Matinya Makna. Yogyakarta: Jalasutra.

7. Schechner, R. (2013). Performances Studies: An Introduction. (Third Edition).London.UK: Routledge.

8. Shoon Choon Wee. (2001). Pengarahan Teater: Suatu Kajian Tentang Sumbangan Krishen Jit. Penyelidikan Tesis Sarjana Muda Kesusasteraan. Fakulti Sastera dan Sains Sosial. Universiti Malaya.

9. Syarul Fitri Musa \& Mohd Effindi Shamsudin. (2019). Konsep Minimalisme dalam Aspek Sinographi Teater Alternatif Melayu di Stor DBP. Journal Ilmiah Ilmu Ilmu Humaniora. Pusat Kajian Humaniora. Vol 17. No 1,2018. pp:53-72. ISSN:2928-3936 